\title{
Disaggregation of Annual to daily Streamflows: A lineardeterministic method
}

\author{
Shatha H. D. Al-Zakar ${ }^{1,3}$, N. Şarlak ${ }^{2}$ \\ ${ }^{I}$ (Department of Dams and Water Resources Engineering, Mosul University, Mosul, Iraq) \\ ${ }_{2}^{2}$ (Department of Civil Engineering, Karamanoglu MehmetbeyUniversity, Karaman, Turkey) \\ ${ }^{3}$ (Department of Civil Engineering, Gaziantep University, Gaziantep, Turkey)
}

\begin{abstract}
In this study, a linear deterministic methodis applied to disaggregate streamflow from annual to daily data inunregulated stations located on the Klzllirmak river in Turkey. To disaggregate annual streamflows to the daily flow at the target station (TS), annual counterparts at the source station (SS) were identified depending on the minimum error criteria that is estimated based on the volume of three-year time window. Then, daily streamflow indexes at SS were calculated to disaggregate annual to daily streamflow at TS through the process. The same steps are replicated to disaggregate monthly streamflow to the daily flow for the purpose of comparison between the two methods. The results are well represents daily streamflow at two methods inquiry comparing to observe data, and also maintain the time series statistical characteristics and mass equilibrium. The comparative results suggest that the monthly to daily disaggregation method perform better than annual to the daily disaggregation method. The daily streamflow generated in this study can be used in the future research for water resources planning and management.
\end{abstract}

Keywords: Streamflow disaggregation, yearly to daily streamflow, flow index

\section{Introduction}

Streamflow disaggregation at small time scales (e.g. daily) is an important research in planning and managing water resources, including, study of the quality water and operation of the reservoir. Many approaches have been utilized to disaggregate streamflow at single and multisites, but little approaches applying based on the streamflow characteristics firmed in the physical computation. An ample models was utilized in the past to produce the finer scale like daily.

At first, the parametric models have been used to disaggregate streamflow to multi-time scale at single and multiple sites [1]. Then this model has been developed as a framework where streamflow sequences are aggregated and then disaggregated into component flows [2, 3, and 4]. The parametric disaggregation approaches depend on some variables, and linear models and on the assumption that the data are normally distributed. However, [5] suggest that most of these approaches are regarded not suitable at short time scales that are less than a month.

Several non-parametric techniques [6,7,8, and 9] have been developed to avoid the parametric limitations in generating streamflow. The non-parametric approach was utilized by [7] including Kernel density estimation approach. This approach was improved by using K-nearest neighbor (KNN) approach based on resampling model by [8]. They claimed that the model is a more flexible model with less mathematical computations. The KNN approach, suggested by [5] was found to be effective in reproducing daily data at multiple sites, and preserving aggregation, continuity, and cross correlation between stations. However, this method does not capture the flow continuity between the first month of the year and the last month of the previous year and it is more appropriate at unregulated streamflow stations. The problem of not capturing flow continuity between monthly or annual transitions in non-parametric approaches are the same as for the parametric approaches. Most of the studies debated above were found to be efficient in bigger time scales from annual or seasonal to monthly. For stochastic models, which were used to disaggregate monthly to daily streamflow, every model has advantages and disadvantages in terms of precision and limitations. The approach developed by [9] was regarded intensive with a larger number of chosen variables. A Markov autocorrelation pulse model developed by [10] and cross-correlation pulse model [11], are able to reproduce the same characteristics of the observed daily streamflow series. These models produce better streamflow disaggregation results at some watersheds, while the simulation of extreme hydrologic events remains limited for wide applications.

In addition, the deterministic approaches were used to generate daily streamflow with restricted application. The disaggregation modelsuggested by [12] to generate daily streamflow by using a deterministic approach depended on the monthly hydroghraph shape selected from observed data that will be closer to the monthly hydrograph intended to be disaggregated. Selecting this hydrograph is based on the least square error statistic, then the daily streamflow are generated depending on the selected monthly hydrograph. Also, anon-linear deterministic approach was used [13] to generate consecutive daily streamflow series by doubling the time 
between one day and 16 days in four cases. Their method provided a good results between the observed and modeled values at low embedding dimensions ( 2 or 3 days) and the precision became better when the time scales changed from bigger to smaller (16 days to 2 days). Another deterministic technique was suggested by [14] depending on the selectionof a single month randomly to downscale monthly precipitation and temperature data to daily data. A similar technique was utilized by [15], but identified a three months to disaggregate monthly to daily streamflow data at the target station (TS) depending upon the selected monthly data at the source station using the root mean square error (RMSE) of three-month window to capture monthly flow volume as approved by [9]. Therefore, the statistical distribution and other significant properties from the resulting streamflow should capture attribute of the historic streamflow [6]. However, most of these methods, which are utilized in disaggregating streamflow at a smaller time scale, are considered insufficient to disaggregate streamflow directly from annual to daily.

As such, the aim of this research is togenerate daily streamflow values from annual streamflow data by employing a linear deterministic methodindisaggregation processes with no complex statistical computations. For the purpose of the present study, annual historical data of the unregulated stations in the Kiz1lirmak Basin (Turkey) are presented to show the utility and the limitations of this approach.

\subsection{Annual to daily disaggregation model}

\section{П. Methodology}

The disaggrgation model applied in this paper is a linear deterministic method to disaggregate annual to daily streamflow at the target station (TS) depending on the selected annual streamflow at the source station (SS) by using the minimum error criterion. The whole steps of this disaggregation process are summarized as follows:

1. Select the source station SS and the target station TS.

2. The source station involves both daily and annualobserved streamflow data.

3. The target station has annual streamflow data only.

4. Daily streamflow at the TS is estimated by using the annual streamflow at TS and the annual and daily streamflow at the SS.

5. A year is selected to be disaggregted at the TS, a 3-year window centering the chosen year at the TS is selected from the annual observed streamflow at the SS.

6. The total annual streamflow from the window at the TS is compared with the samewindow from the available historical record at the SS.

7. Compute the RMSE to find the bestcoincide year between the TS and the SS.

8. Estimate the daily flow index (SIss) as the ratio of daily flow to annual flow of the selected year at (SS). Streamflow daily index (SIss) $=\frac{\text { Daily streamflow at (SS) }}{\text { Annual streamflow at (SS) }}$

9. The disaggregation of the daily flow at the TS is computed as:

Disaggregation of the daily streamflow at (TS) $=$ SIss* annual streamflow at $(\mathrm{TS})$

10. Steps(1-9) are repeated to disaggregate other years.

The cubic spline interpolation was employed as a tool to adjust the disaggregation data when the difference between any two flow months through the year are more than $10 \%$, which is known as a the threshold and which depends on engineering opinion. The $10 \%$ threshold is agreed if the total monthly flow is similar before and after applying the interpolation. However, the cubic spline is applied to reduce the hydrologic jumps between any two consecutive months. For this aim, the last 7 disaggregated daily streamflows for the selected month and the first 7 days of the following month are submitted to cubic spline interpolation. For example, to reduce the difference in flows between April and May 1999, a time widow, April 24-30 and May 1-7, was chosen to interpolate from the spline. However, the interpolated streamflow length is less than $25 \%$ of the two months time window (14 from 60 days), while the monthly flow (aggregated daily flows) before and after smoothing method should not significantly differ, so that the spline can preserve the summability comparatively well in this case. Sometimes the splines create negative values through a very low flow situation. In this case, the logspline method can be used [16].

\subsection{Disaggregation model from monthly to daily flow}

To disaggregate monthly to daily flow, the same steps of thedisaggregation streamflow from annual to daily method are applied. Currently, a 3-month window is taken in this case for the month that requires disaggregation to daily flow. The choice of historical monthly streamflow matching with the same monthly window is also based on the relative error criteria by using RMSE. The SS in this model must include both daily and monthly historical streamflow, while the TS has only monthly streamflow. The daily streamflow at the TS 
is estimated depending on it is monthly flow and on monthly and daily flow at SS. At the beginning, a year and a month were identified for disaggregation at the TS, then a 3-month window centering the selected month at the TS is chosen from historic monthly streamflow record at the SS. For example, streamflow disaggregation in May at the TS needs flow data for a 3-month window, including April, May, and June, over historic recorded monthly streamflow at the SS. So, the total monthly streamflow for these three months at the TS is used to be compared with the same months in windows for each year of the observed record existing at the SS. Next, the same steps are replicated as described above in Section 2.1 to complete the disaggregation process.

\section{III.Study Area}

Two pairs of unregulated streamflow gauging stations located along the Kızllirmak River are selected for the purpose of disaggregation in this study, (Figure 1). The first selected pair streamflow stations, Yahsihan (EIE 1503) and Yamulu (EIE 1501), are located on the main river. EIE 1503 station is located downstream of the existing dams (Hirfanli, Kesikköprü, and Kapulukaya).Since the observed streamflows data of station EIE 1503 have been influenced by the existing dams, unaffected flows of this station should be obtained. Station EIE 1501 , located at the upstream of the dams was used as a reference to obtain the natural streamflow values (unaffected form) of the station by obtaining the correlation coefficient between observed data of these stations before the construction of the dams. The second selected pair of streamflow gauge stations, Sefaatli (EIE1517) and Cadirhoyuk (EIE 1541), are located at the biggest tributary (Delice river) of the main river. No diversions are constructed at the upstream of these stations, [17]. The detailed information, including latitude, longitude, elevation and observation period, are listed in Table 1. Historical yearly and daily streamflow data for the selected stations are provided by the General Directorate of State Hydraulic Works (DSI).

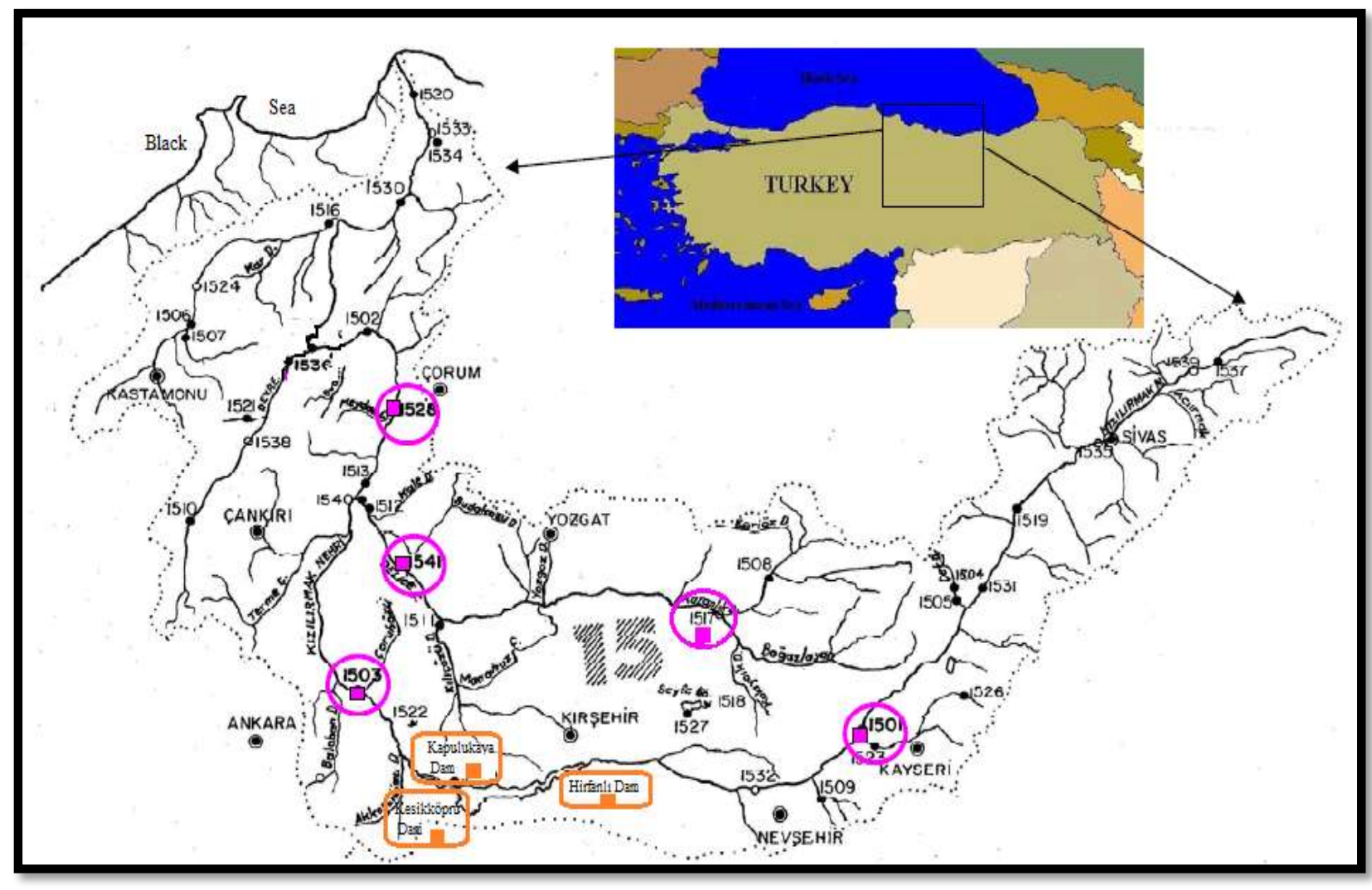

Figure 1: Gages station schematic: (1) EIE1541; (2) EIE1517; (3) EIE 1503; (4)EIE1501

Table 1: Gauge Stations name and characteristics of streamflow used in the study

\begin{tabular}{|l|l|c|c|c|}
\hline Station Name & Latitude & Longitude & Date & Status \\
\hline 1501-Yamulu & $35^{\circ} 15^{\prime} 31^{\prime \prime}$ & $38^{\circ} 53^{\prime} 25^{\prime \prime}$ & $1939-2002$ & Source Station \\
\hline 1503-Yahsihan & $33^{\circ} 28^{\prime} 54^{\prime \prime}$ & $39^{\circ} 50^{\prime} 36^{\prime \prime}$ & $1939-2002$ & Target Station \\
\hline 1517-Sefaatli & $34^{\circ} 44^{\prime} 51^{\prime \prime}$ & $39^{\circ} 30^{\prime} 14^{\prime \prime}$ & $1964-2002$ & Source Station \\
\hline 1541-Cadirhoyuk & $34^{\circ} 07^{\prime} 09^{\prime \prime}$ & $40^{\circ} 18^{\prime} 31^{\prime \prime}$ & $1981-2002$ & Target Station \\
\hline
\end{tabular}

As, the gauge stations EIE 1501 and EIE 1503 are located on the main river within a similar watershed, the characteristics of the monthly observed data at the two stationsdisplay similar patterns as shown in Figure 2. The 
gauge stations EIE1501 and EIE1503 are considered as the source station (SS) and target stations (TS), respectively. For the tributary Delice river, the gauge stations EIE 1517 and EIE 1541 are selected as SS and TS, respectively. Both of these stations are sited at the same basin and show a similar shape of hydrography, as seen in Figure 3.

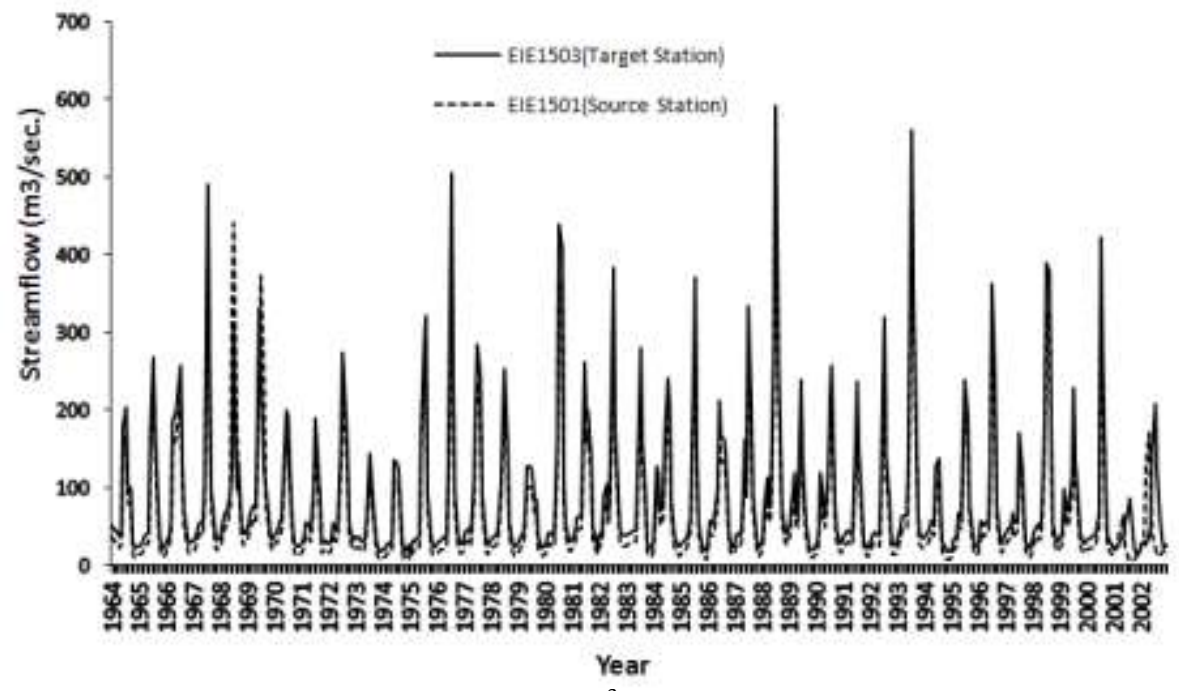

Figure 2: Mean monthly observed streamflow $\left(\mathrm{m}^{3} / \mathrm{sec}\right)$ for the target station EIE1503 and source station EIE 1501.

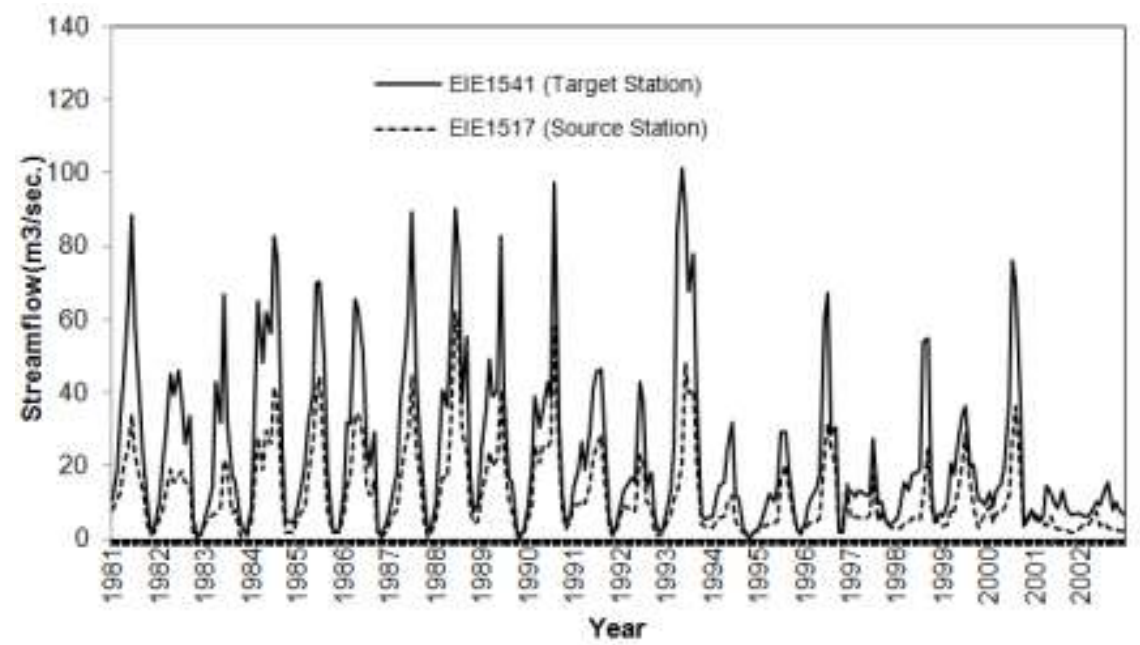

Figure 3: Mean monthly observed streamflow $\left(\mathrm{m}^{3} / \mathrm{sec}\right)$ for the target station EIE 1541 and source station EIE 1517.

\section{IV.Results and Discussion}

\subsection{Annual to daily disaggregation daily results}

For the first pair of stations on the main river, six years (1995-2000) of streamflow at the target station EIE 1503 are utilized in the disaggregation process based on 64 years (1939-2002) of daily and yearly streamflow at the source station EIE1501. The disaggregated daily flows were aggregated to form monthly flow for the purpose of comparison with the historical monthly data at the same period. Both historical and dissagregated daily streamflow data matched well, indicating that low and high flows are captured well. It appears that the disaggregated high flows are a bit greater than the historical peak flows as shown in Figure 4. The calculated statistics[18,19] between the historical and the disaggregated streamflow values can be deemed good in the analysis. A small positive bias, higher correlation and Nash Sutclliffe Efficiency (Bias\%=0.082, $r=$ $0.852, \mathrm{R} 2=0.726, \mathrm{NSE}=0.677$ ) were found with the Root Mean Square Error (RMSE) of $38.175 \mathrm{~m} 3 / \mathrm{sec}$ through the disaggregation process. After the cubic spline interpolation is applied, the calculated statistics are available in Figure 4. It can be seen theless bias $(0.038 \%)$, and the increased correlation and Nash Sutclliffe Efficiency $\left(r=0.954, \mathrm{R}^{2}=0.910, \mathrm{NSE}=0.909\right)$ are getting with the decreased (RMSE $\left.=25.33\right)$, which indicate that the application of cubic spline led to smooth hydrograph and reduce the peak flows during the move between months. The positive bias (\%) statistic denotes that the disaggregation streamflows are greater than the 
historical flows. Also, the historical and disaggregated mean daily streamflow obtained for each month is identical, while the standard deviation through Febuary-June are higher relatively than that through July-January (Table 3). In general, the high standard deviation is shown during high flows.

Boxplots in Figure 5 show the comparison between the range of historical and dissagregated monthly streamflow through the period 1995-2000. The maximum, the minimum, the range of interquartile, and the median is very well matched during the low flow months, while a difference in maximum and minimum range can be seen in March, April and May. Also, the outliers have a similar magnitude.

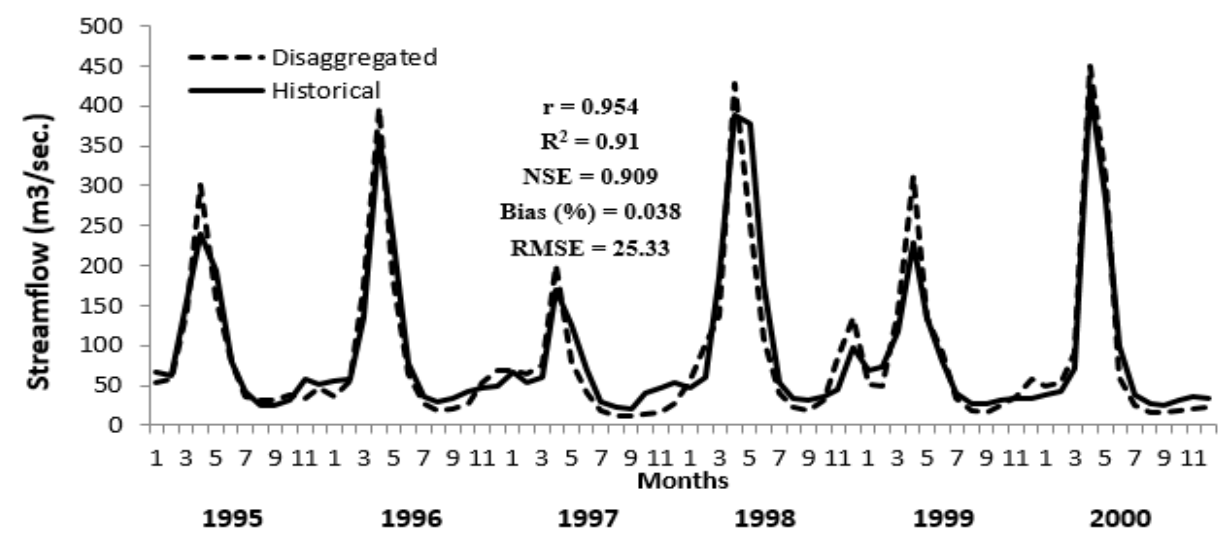

Figure4: Disaggregated and historical daily streamflows at EIE1503 during the period 1995-2000. After using a cubic splin interpolation.

Table 2: Monthly mean and standard deviation (Std) for both observed and disaggregated streamflow at station

\begin{tabular}{|c|c|c|c|c|}
\multicolumn{1}{c}{} & \multicolumn{4}{c|}{ EIE 1503 during $(1995-2000)}$. \\
\cline { 2 - 5 } & \multicolumn{3}{c|}{$\begin{array}{c}\text { Observed flow } \\
\left(\mathrm{m}^{3} / \mathrm{sec}\right)\end{array}$} & \multicolumn{2}{c|}{$\begin{array}{c}\text { Disaggregated flow } \\
\left(\mathrm{m}^{3} / \mathrm{sec}\right)\end{array}$} \\
\cline { 2 - 5 } & Mean & Std & Mean & Std \\
\hline Months & 57.1 & 12.6 & 57.2 & 13.3 \\
\hline Jan & 60.5 & 18.2 & 60.2 & 22.2 \\
\hline Feb & 121.0 & 37.1 & 120.1 & 48.8 \\
\hline Mar & 301.7 & 99.3 & 297.5 & 102.3 \\
\hline Apr & 225.1 & 84.5 & 226.8 & 95.3 \\
\hline May & 97.2 & 40.1 & 94.6 & 35.6 \\
\hline Jun & 40.2 & 7.5 & 41.4 & 8.0 \\
\hline Jul & 27.8 & 3.9 & 28.1 & 7.0 \\
\hline Aug & 27.4 & 6.7 & 30.2 & 4.4 \\
\hline Sep & 36.0 & 4.5 & 36.3 & 8.3 \\
\hline Oct & 44.7 & 8.6 & 41.2 & 15.3 \\
\hline Nov & 53.7 & 23.3 & 51.2 & 31.1 \\
\hline Dec & & & & \\
\hline
\end{tabular}

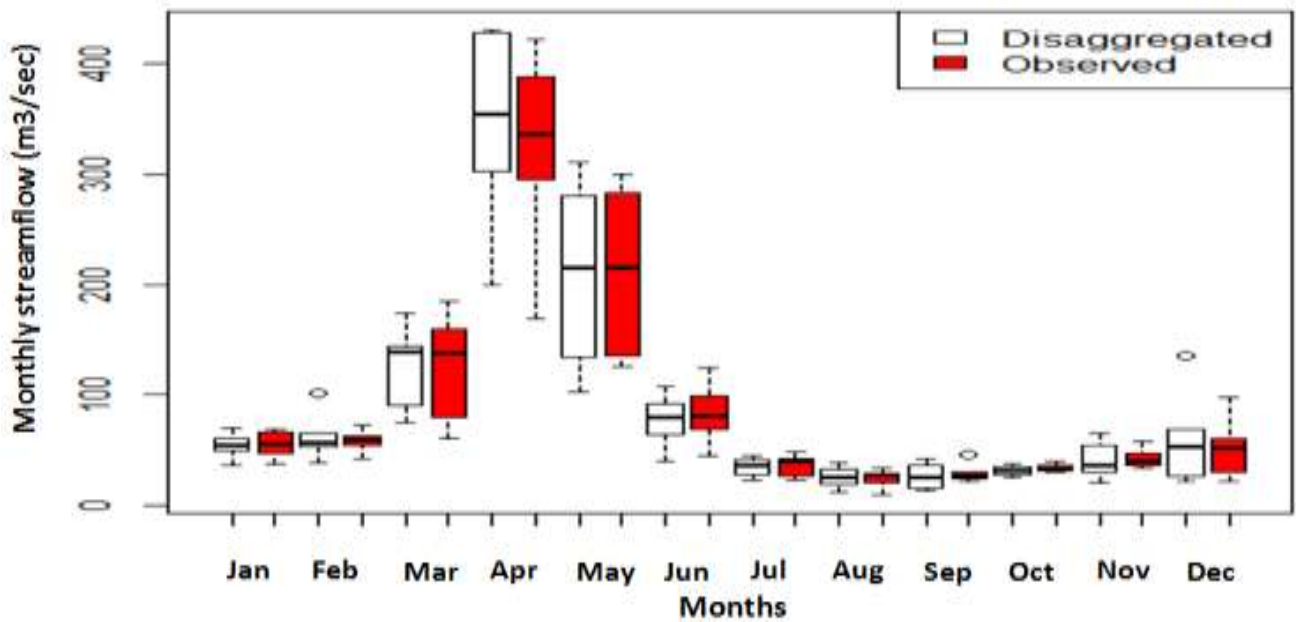


Figure5: Boxplots presenting a variation in disaggregation(left) and historical(right) monthly streamflow during 1995-2000 for station EIE1503.

For the second pairs of streamflow at the tributary (Delice river), the disaggregation procedure is employed also to disaggregate six years (1995-2000) of daily streamflow at EIE1541 depending on 39 years (1964-2002) of daily and yearly streamflow at EIE1517. The dissagregated daily flows obtained are summed to form monthly data that are compared with the historical data at the same period of the study as shown in Figure 6. The comparison illustrates that the peaks and the bases of the streamflow of the hydrograph are well captured except an abnormal peak through the period of April-June in 1999 as shown in Figure 6. A cubic spline interpolation is used as a post process to avoid variance between the historical and the disaggregated values of this period. It can be seen that the disaggregation at lower peak flow are a bit higher than the observed ones because streamflow at source station oftentimes exceeds the streamflow at the target station through the disaggregation process.

The statistics computed from historical and disaggregated monthly streamflow during the period 19952000 are listed in Figure 6 after cubic splin applicated. The statistical results from this pair show lower bias\%, r, $\mathrm{R}^{2}$, NSE, and RMSE in comparison with the first pair. This can be attributed, to the differences in the hydrological characteristics of the locations of stream gauge stations and catchment areas. Also, the mean disaggregated daily streamflow obtained for each month over the study period are in a similar run, except April, that show some difference. Overall, the standard deviations through March-June are higher in comparison with July-Feburary, as shown in Table 3.

The Boxplots in Figure7 shows interquartile range, maximum and minimum streamflow, and the median for each month during the period 1995-2000. The median and interquartile range of monthly streamflow are almost in the same domain for all months except March through May, where the median daily historical streamflow is higher than that of the disaggregated streamflow. Also, the maximum and the minimum streamflow have been approximately within the same range for all months excluding March-May, where the disaggregated data showed a high range of streamflow as comparing to the historical streamflow. This high disaggregated streamflows are due to the higher ratio (SIss) obtained, which is related to the higher streamflow at SS. In general, the disaggregated streamflow matches well with the historical streamflow.

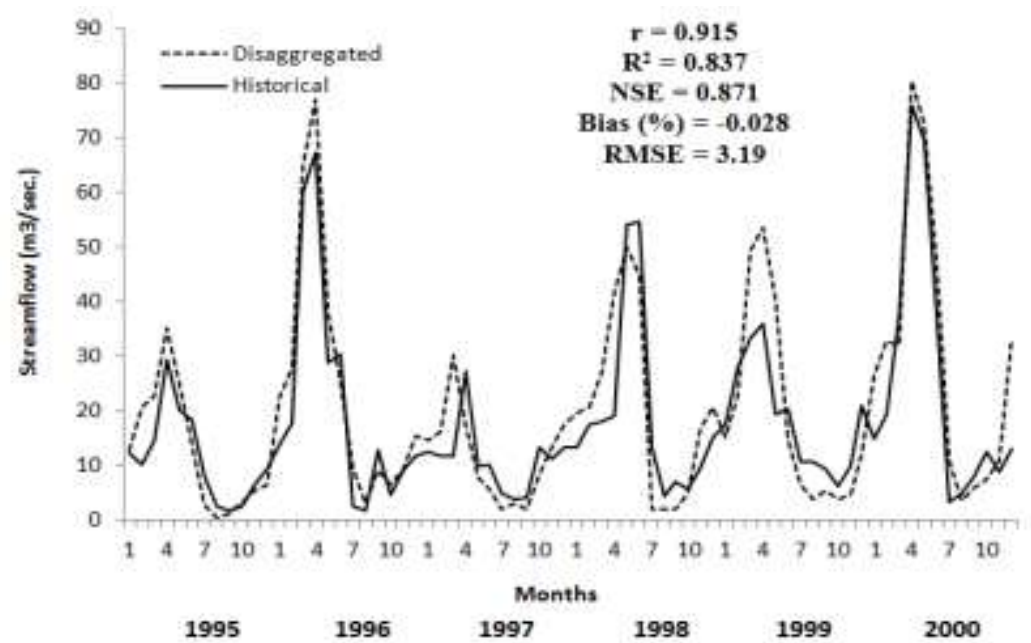

Figure6: Disaggregated and historical daily streamflows at EIE1541 during the period 1995-2000

Table3: Monthly mean and standard deviation (Std) for both observed and disaggregated streamflow at station EIE 1541 during (1995-2000)

\begin{tabular}{|c|c|c|c|c|}
\hline \multirow[b]{3}{*}{ Months } & \multicolumn{4}{|c|}{ EIE 1541} \\
\hline & \multicolumn{2}{|c|}{$\begin{array}{c}\text { Observed flow } \\
\left(\mathrm{m}^{3} / \mathrm{sec}\right)\end{array}$} & \multicolumn{2}{|c|}{$\begin{array}{l}\text { Disaggregated flow } \\
\left(\mathrm{m}^{3} / \mathrm{sec}\right)\end{array}$} \\
\hline & Mean & Std & Mean & Std \\
\hline Jan & 19.16 & 1.81 & 18.60 & 4.81 \\
\hline Feb & 17.52 & 5.79 & 17.34 & 5.38 \\
\hline Mar & 29.33 & 16.77 & 28.95 & 10.67 \\
\hline Apr & 42.53 & 21.25 & 40.53 & 14.00 \\
\hline May & 35.24 & 20.49 & 35.18 & 20.90 \\
\hline Jun & 28.65 & 14.55 & 29.23 & 12.80 \\
\hline Jul & 7.17 & 3.91 & 7.49 & 3.58 \\
\hline Aug & 4.77 & 2.87 & 6.23 & 1.12 \\
\hline Sep & 7.24 & 3.56 & 7.32 & 2.78 \\
\hline Oct & 7.54 & 4.05 & 7.62 & 5.86 \\
\hline
\end{tabular}




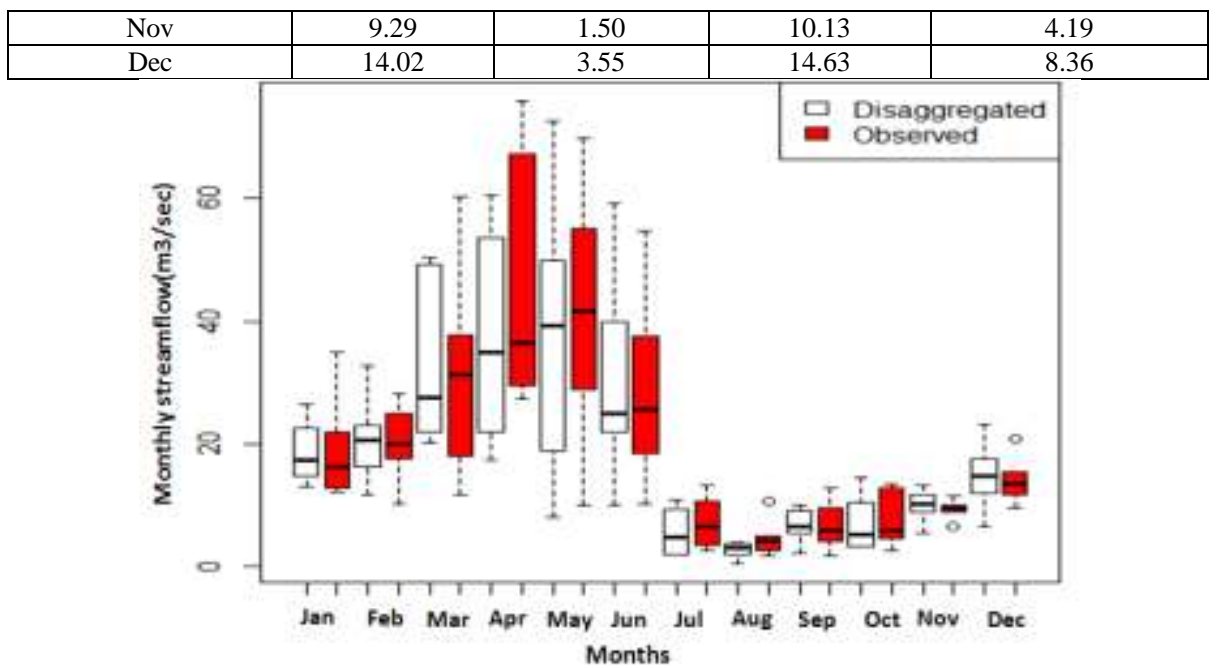

Figure7: Boxplots presenting a variation in disaggregation(left) and historical(right) monthly streamflow during 1995-2000 for station EIE1541.

The two-sample Kolmogorov-Smirnov (K-S) nonparametric test is applied for each pairs station in the study to find if the historical and disaggregated streamflow distribution is significantly different[20]. The K-S test showed that, the null hypothesis of the historical and disaggregated streamflow are at the 5\% level of significance. The null hypothesis shows that the cumulative distribution (cdf) of the disaggregated data is less than that of the observed data; the alternative is that the hypothesis of the cumulative distribution (cdf) of the disaggregated data is more than that of the observed data. The results show the acceptance of null hypothesis due to the value of $\left(D_{\text {stat }}=0.0986\right.$ and 0.02186$)$ which is less than $(\mathrm{Dc}=1.9344)$ for EIE1541 and EIE1503 stations, respectively. Also the "p" value was more than 0.5 in each pair of selected streamflows.

\subsection{Monthly to daily disaggregation results}

The monthly streamflow data of the same five years (1995-2000) from the target station (EIE 1503) are utilized in the disaggregation process depended on 64 years (1939-2002) of daily and monthly streamflow at the source station (EIE1501). The disaggregated daily flows obtained at EIE1503 station are aggregated to get monthly flow for the purpose of comparison with the historical monthly data at the same period. Both historical and desegregated daily streamflow data were found to match very well and the low and high flows are captured well (Figure 8), since the two stations are located in the same watershed. The calculated statistics between the historical and disaggregated streamflow values are illustrated in Figure 8. The statistics results showa very good match between the historical and disaggregated values due to the higher values of correlation coefficient (r), coefficient of determination $\left(\mathrm{R}^{2}\right)$ and Nash-Sutcliffe efficiency (NSE). The very low positive of bias (\%) denotes that the disaggregation flows are higher than the historical flows. The historical and disaggregated mean value of daily streamflow obtained for each month is almost equal, while the standard deviation obtained from disaggregated values are relatively higher than that of the historical one in most of months (Table 4).

Boxplots in Figure 9 show a comparison range of historical and dissagregated monthly streamflow through the period 1995-2000. The range of minimum, maximum, and median flow is very well balanced for all months, especially during the low flow months. The wider boxplots in April and May indicate the variety of flow values obtained from both historical and disaggregation values. Also the outliers show a similar magnitude.

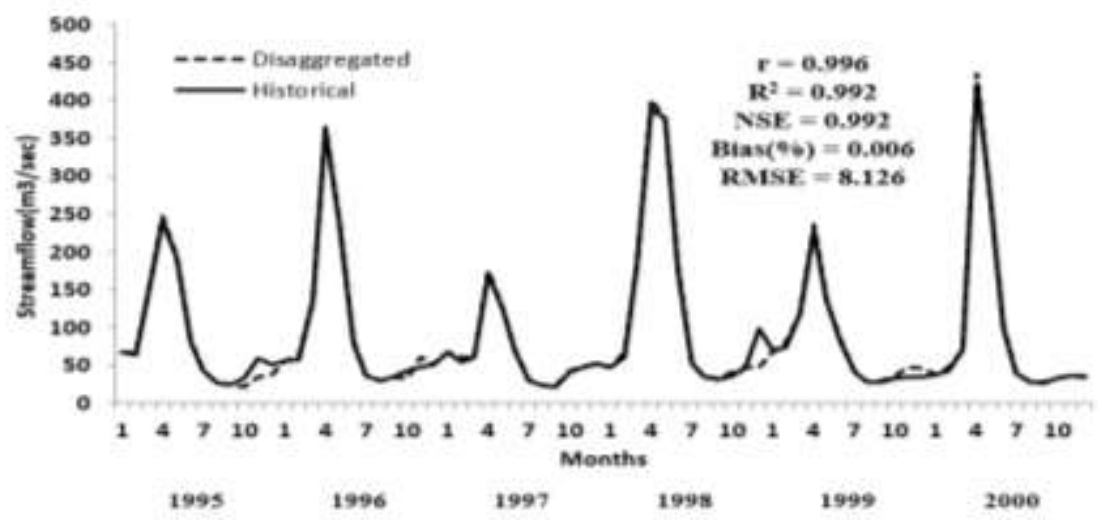


Figure 8: Disaggregated and historical daily streamflows at EIE1503 during the period 1995-2000

Table 4: Monthly mean and standard deviation (Std) for both observed and disaggregated streamflow at station EIE 1503 during (1995-2000).

\begin{tabular}{|c|c|c|c|c|}
\cline { 2 - 5 } & \multicolumn{3}{c|}{\begin{tabular}{c} 
EIE 1503 \\
\cline { 2 - 4 }
\end{tabular}} & \multicolumn{2}{c|}{$\begin{array}{c}\text { Observed flow } \\
\left(\mathrm{m}^{3} / \mathrm{sec}\right)\end{array}$} & Mean & Std \\
\cline { 2 - 5 } & Mean & Std & 57.12 & 11.56 \\
\hline Months & 57.1 & 12.6 & 63.95 & 20.2 \\
\hline Jan & 60.5 & 18.2 & 120.53 & 37.8 \\
\hline Feb & 121.0 & 37.1 & 299.75 & 102.3 \\
\hline Mar & 301.7 & 99.3 & 225.01 & 84.3 \\
\hline Apr & 225.1 & 84.5 & 100.39 & 41.8 \\
\hline May & 97.2 & 40.1 & 40.18 & 7.4 \\
\hline Jun & 40.2 & 7.5 & 27.76 & 3.95 \\
\hline Jul & 27.8 & 3.9 & 28.33 & 6.9 \\
\hline Aug & 27.4 & 6.7 & 36.39 & 4.3 \\
\hline Sep & 36.0 & 4.5 & 45.54 & 8.8 \\
\hline Oct & 44.7 & 8.6 & 53.37 & 23.9 \\
\hline Nov & 53.7 & 23.3 & & \\
\hline Dec & & & & \multicolumn{2}{c|}{} \\
\hline
\end{tabular}

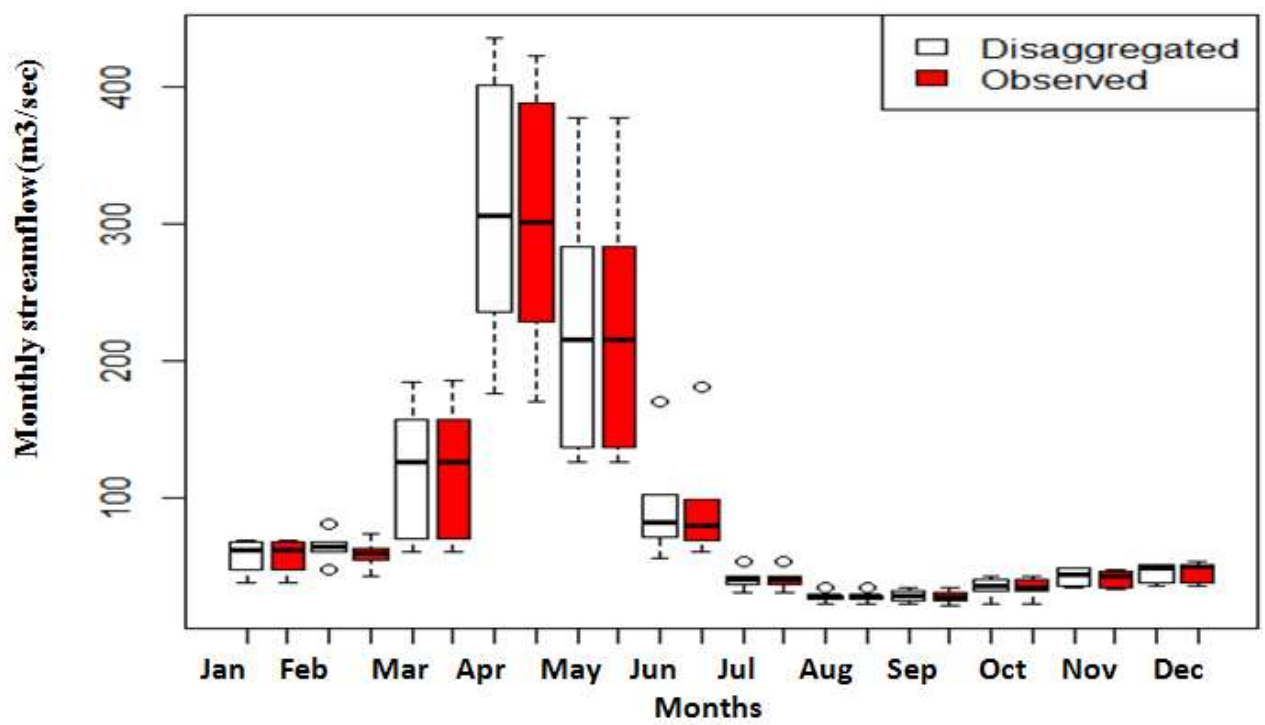

Figure 9: Boxplots presenting a variation in disaggregation(left) and historical(right) monthly streamflow during 1995-2000 for station EIE1503.

For the second pair of stations, the disaggregation procedure is applied to disaggregate the monthly streamflow of the six years (1995-2000) to daily data streamflow at EIE1541 based on the monthly and daily streamflow at EIE1517. The dissagregated daily flows obtained are aggregated back to form monthly data to be compared with the historical data of the same period as shown in Figure 10. The comparison shows similar hydrograph of the streamflow in both historical and disaggregated data. This suggests that approximately the same base and peak streamflows are very well captured. So, A cubic spline is not needed in this case.

The statistics computed from historical and disaggregated monthly streamflow during the period 19952000 are listed in Figure 10. It can be seen that the statistics show lower bias\%, and RMSE than the first method, while the $r, \mathrm{R}^{2}$, and NSE are higher in comparison with the statistics obtained from annual to the daily disaggregation method as shown in Figure 6. Also, the mean disaggregated daily streamflow obtained for each month over the study period are in a similar run in all months (Table 5). Overall, the standard deviations obtained from disaggregation values are found to be slightly higher than the historical one as shown in Table 5 .

Boxplots in Figure 11 show interquartile range, maximum and minimum flow, as well as the median flow for each month during the period 1995-2000. The median and interquartile range of monthly streamflow are almost in the same domain for all months. Also, the maximum and minimum streamflow have been approximately within the same range for each month. In general the disaggregated streamflow matches well with the historical streamflow. 


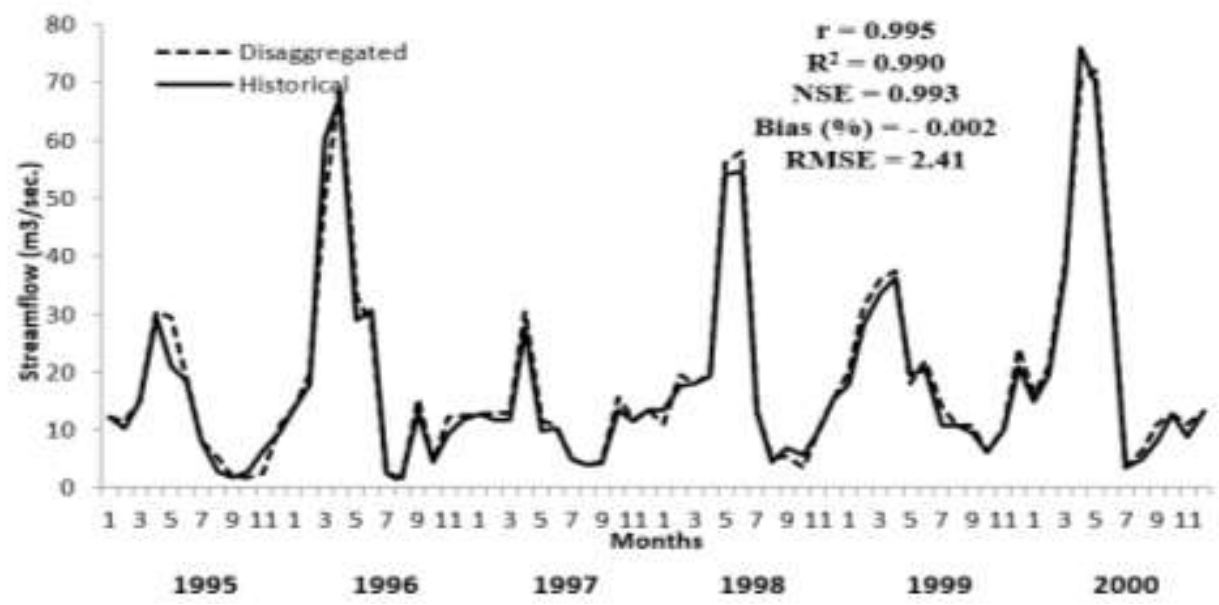

Figure 10: Disaggregated and historical daily streamflows at EIE1541 during the period 1995-2000

Table 5: Monthly mean and standard deviation (Std) for both observed and disaggregated streamflow at station

\begin{tabular}{|c|c|c|c|c|}
\multicolumn{1}{c}{} & \multicolumn{4}{c|}{ EIE 1541 during (1995-2000). } \\
\cline { 2 - 5 } & \multicolumn{3}{c|}{$\begin{array}{c}\text { Observed flow } \\
\left(\mathrm{m}^{3} / \mathrm{sec}\right)\end{array}$} & \multicolumn{2}{c|}{$\begin{array}{c}\text { Disaggregated flow } \\
\left(\mathrm{m}^{3} / \mathrm{sec}\right)\end{array}$} \\
\cline { 2 - 5 } & Mean & Std & Mean & Std \\
\hline Months & 19.16 & 1.81 & 19.03 & 1.98 \\
\hline Jan & 17.52 & 5.79 & 17.3 & 4.44 \\
\hline Feb & 29.33 & 16.77 & 28.5 & 13.36 \\
\hline Mar & 42.53 & 21.25 & 43.9 & 24.05 \\
\hline Apr & 35.24 & 20.49 & 36.7 & 21.04 \\
\hline May & 28.65 & 14.55 & 29.4 & 16.41 \\
\hline Jun & 7.17 & 3.91 & 7.12 & 4.28 \\
\hline Jul & 4.77 & 2.87 & 4.79 & 3.14 \\
\hline Aug & 7.24 & 3.56 & 7.49 & 4.03 \\
\hline Sep & 7.54 & 4.05 & 7.42 & 4.44 \\
\hline Oct & 9.29 & 1.50 & 9.37 & 3.47 \\
\hline Nov & 14.02 & 3.55 & 14.08 & 3.89 \\
\hline Dec & & & & \\
\hline
\end{tabular}

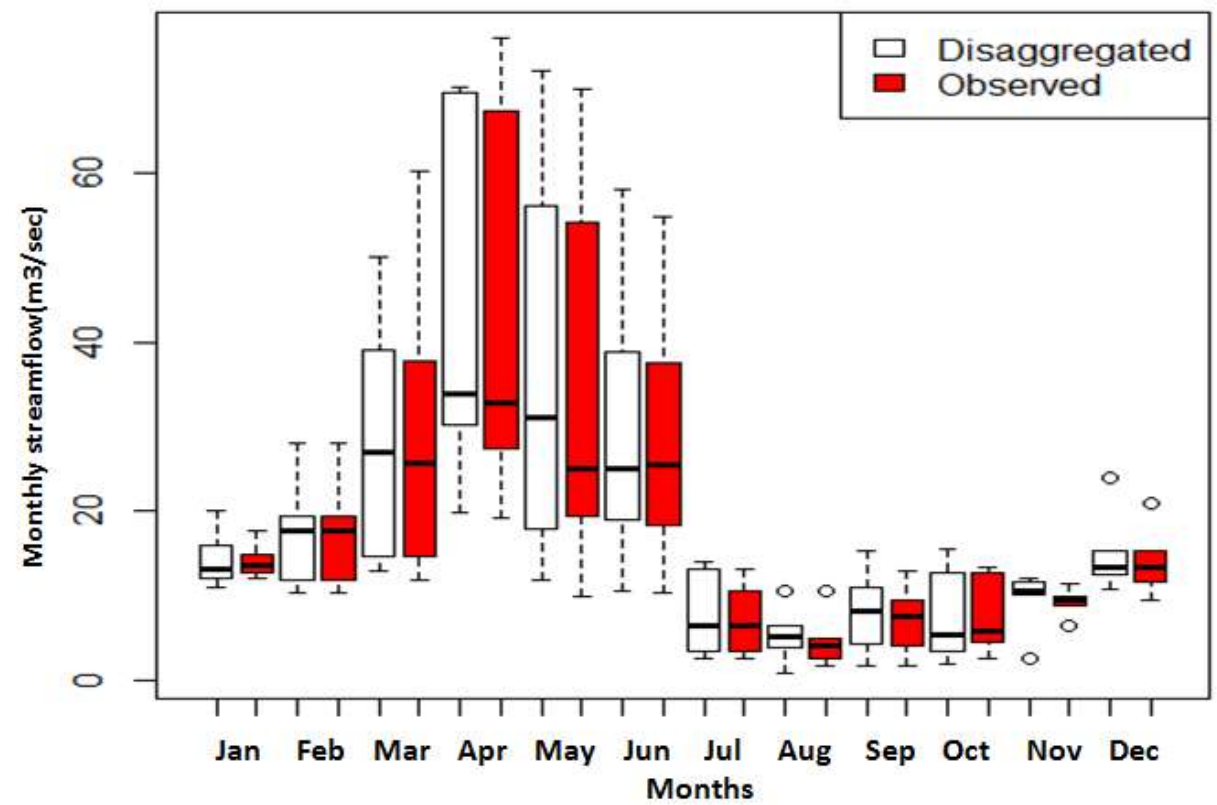

Figure 11: Boxplots presenting a variation in disagregation (left) and historical (right) monthly streamflow during 1995-2000 for station EIE1541. 


\section{Conclusions}

This study utilizes statistical methods to disaggregate streamflow directly from yearly to daily data and from monthly to daily data. The main restriction on these methods is the selection of a source station and a target station that are linked to the availability of yearly or monthly, and daily streamflow at source station. The results may be biased depending on the selected source station and also affected by missing historical records. The appropriateness of these disaggregation methods has been shown through its application at unregulated watersheds in Turkey. Visual check and statistical parameters were employed to evaluate the hydrograph of the historical and disaggregated data of streamflow. Generally, the magnitudes and the outlines of the disaggregated streamflow are well correlated with the observed streamflow in the two models for the period of study. Monthly statistics show that the disaggregation from annual to monthly are better performed than that from annual to daily. Also, statistics show that the disaggregation of station EIE1503 at the main river is better performed than that for an EIE1541 station on the tributary river. Apparently, the value of RMSE varies depending on the streamflow at SS, so the high streamflow has produced the highest RMSE as shown on EIE1503 station. For the annual to daily disaggregation, the K-S nonparametric test showed that the (cdf) of the historical streamflow is wider than the disaggregation ones in the two pairs of streamflow at $5 \%$ significance level.

The objective of this research is to disaggregate streamflow from yearly to daily and from yearly to monthly using less computations and time as possible, to be applied in areas where a short timescale data may not be available. In conclusion, this tool can be applied directly at any location to disaggregate streamflow from higher to lower timescals. Thus, these methods could help make decisions in evaluating future streamflow data for this region in Turkey and could be used as a tool in water resource management and planning.

\section{References}

[1]. D.Valencia, and J. C. Schaake. Disaggregation processes in stochastic hydrology,Journal of Water Resources Research, 9(3), 1973, 580-585.

[2]. J. D. Salas, J. W. Delleur, V. Yevjevich, and W. L. Lane,Applied Modeling of Hydrologic Time Series, (Water Resources Puplications, LLC, Colorado, 1980).

[3]. J. C., Grygier, and J. R. Stedinger, Condensed disaggregation procedures and conservation corrections for stochastic hydrology, Water Resour. Res.,24, 1988,1574-584.

[4]. S. Maheepala, and B. J. C. Perera, Monthly hydrologic data generation by disaggregation.J. Hydrol., 178(1-4), 1996, $277-291$.

[5]. K. Nowak, J. Prairie, B. Rajagopalan and U. Lall,A nonparametric stochastic approach for multisite disaggregation of annual to daily streamflow, Water Resources research. 46(8), 2010.

[6]. D. G. Tarboton, A. Sharma, and U. Lall,Disaggregation procedures for stochastic hydrology based on nonparametric density estimation, Journal of Water Resource Research, 34(1), 1998, pp. 107-119.

[7]. J.Prairie, B.Rajagopalan, U. Lall, and T. Ful,A stochastic nonparametric technique for space-time disaggregation of streamflows,Journal of Water Resources Research,43(3), 2007.

[8]. T. Lee, J. D. Sales, and J. Prairie, An enhanced nonparametric streamflow disaggregation model with genetic algorithm, Water Resour. Res.,46 (8), 2010.

[9]. D. Nagesh Kumar, U. Lal,M. R.Petersen, Multisite disaggregation of monthly to daily streamflow,Water Resour. Res.,36 (7), 2000, 1823-1833.

[10]. Z. Xu, A. Schumann, and C. Brass,Markov autocorrelation pulse model for two sites daily streamflow, J. Hydrol. Eng., 6 (3), 2001,189-195.

[11]. Z. Xu, A. Schumann, and J. Li,. Markov cross-correlation pulse model for daily streamflow generation at multiple sites. Adv. Water Resour., 26(3), 2003, 325-335.

[12]. N. K.Ganju, N. Knowles, and D. H. Schoellhamer, Temporal downscaling of decadal sediment load estimates to a daily interval for use in hindcast simulations,J. Hydrol., 349 (3-4), 2008, 512-523.

[13]. B. Sivakumar, W. W.Wallender, C. E.Puente, and M. N.Islam, Streamflow disaggregation: A nonlinear deterministic approach,Nonlinear Process. Geophys.,11 (3), 2004, 383-392.

[14]. A. W. Wood, L. R. Leung, V. Sridhar, and D. P. Lettenmaier, Hydrologic implications of dynamical and statistical approaches to downscaling climate model outputs, Claim. Change, 62 (1-3), 2004, 189-216

[15]. A. Anil, H. R. Jae. A simple method for streamflow disaggregation, Journal of Hydrologic Engineering. 19(3),2014, 509-519.

[16]. B.J.A.Masse, Conditional logspline density estimation,The Canadian Journal of Statistics, 27(4), 1992, 819-832.

[17]. N. Sarlak. Annual Streamflow Modelling with Asymmetric Distribution Function.Hydrological Processes, 22(17),2008, $3403-3409$.

[18]. A. Acharya, T. C. Piechota, H. Stephen, and G. Tootle, Modeled streamflow response under cloud seeding in the North Platte River watershed, J. Hydrol., 409(1-2),,2011, 305-314.

[19]. P., Krause, D. P. Boyle, and F. Base, Comparison of different efficiency criteria for hydrological model assessment. Adv. Geosci.,5, 2005, 89-97.

[20]. A. Acharya, T. C. Piechota, and G.Tootle. Quantitative assessment of climate change impacts on the hydrology of the North Platte River watershed, Wyoming. J. Hydrol. Eng.,17(10), 2012, 1071-1083. 